\title{
The changing context of undergraduate medical education
}

\author{
Glennys J Parsell, John Bligh
}

\begin{abstract}
Summary
It has long been recognised that intensive efforts are needed to reform medical education in order to meet the future needs of populations worldwide. Pressure for changes to the organisation, content and delivery of both undergraduate and postgraduate medical education has greatly increased in the last two decades. The experience of innovative medical schools, the emergence of learner-centred teaching methods and the implications of healthcare reforms in North America and Britain are major factors influencing calls for change. The pace of change has accelerated to such an extent in recent years that progress towards widespread reform appears to be more attainable than ever before. This article provides an overview of the changing context of health-care, some patterns of existing medical education and some strategies for change.
\end{abstract}

Keywords: education, medical undergraduates

University Medical Education Unit, Faculty of Medicine, The University of Liverpool, Liverpool, UK

GJ Parsell

J Bligh

Correspondence to GJ Parsell, University Medical Education Unit, 3rd Floor, UCD Bld, Royal Liverpool University Hospital, Liverpool L69 3BX, UK

Accepted 2 March 1995

\section{A worldwide issue}

Health care has become a central public issue and is no longer seen as the prerogative of doctors or medical schools. ${ }^{1-3}$ Governments, the public and the medical profession recognise that medical education has not kept pace with the health-care needs of populations around the world. Problems in medical education have been clearly documented over many years and efforts are being made to find solutions. ${ }^{4-6}$

These problems include new patterns of disease in developing and developed countries, inadequate health-care systems and a shortage of the right kind of doctors, ie, generalists as opposed to specialists. ${ }^{7}$ Aging populations, chronic disease, and rehabilitation medicine are making increasing demands on health services. Public health issues and social problems such as maternal and child health, AIDS, and alcohol and substance abuse, are presenting major challenges for health-care and for medical education. ${ }^{8-10}$

\section{The health-care context}

In Britain, changes in management structures and funding arrangements have introduced a competitive market economy to the national health-care service. Rapid advances in medical knowledge and technical skills have widened therapeutic and research opportunities. Advances in information technology have increased opportunities for communicating information, sharing ideas and facilitating research. ${ }^{11}$ Government legislation and the Patients' Charter are clearing the way for the public to expect much more from the national health-care system. Increased emphasis on the role of the community in the care of the ill, in preventing disease and promoting health has placed a heavy burden on existing services. ${ }^{12-14}$ As a result, relationships between those involved in health-care are changing, both towards each other and towards patients. If doctors are to function effectively in this new context, their education and training as medical students and professionals must undergo reform.

\section{University medical schools}

The responsibility for producing appropriately trained doctors lies with university medical schools. It is here that educational foundations are established, affecting patient care and community health in the future. The ways in which students are selected and the context, structure, and organisation of curricula have been scrutinised in order to reconcile population needs with appropriate health-care.

\section{STUDENT SELECTION}

In Britain, students can enter medical school at 18 years of age with ' $A$ ' levels obtained at secondary schools. North American schools require students to be graduates and some Australian schools (eg, Queensland, Sydney and Flinders), are preparing for graduate entry in 1996. Some European schools (eg, Belgium and Italy) operate a free admissions policy, selection being achieved through attrition. ${ }^{15}$

Student selection is frequently based on prior academic success, accounting for about $35 \%$ of the variance in medical school performance, but there is increasing evidence that selection based solely on this criterion will not produce the 'best' doctors. ${ }^{16}$ Personal attributes, motivation and non-academic abilities such as communication skills, may be equally important predictors of students becoming effective practitioners. The use of innovative curricula based on problem-based or self-directed study may also mean that student selection should be based on different or broader criteria and that a period of preparation for this form of learning should be provided..$^{17}$ 
Adverse publicity in recent years in Britain about the demanding working conditions and long hours of junior doctors, combined with largely unsupervised hospital-based training, may have reduced the pool of applications to medical schools in Britain. It has been asserted that there are now only two applicants for every place available. ${ }^{18}$ However, this figure has been contested by Deans of medical schools. The issue of selection of undergraduates on the basis of criteria other than examination results may not be an issue at all if the pool begins to evaporate.

\section{BASIC MEDICAL EDUCATION}

European students spend six years $(5500 \mathrm{~h})$ under the umbrella of universities receiving basic medical education prior to registration as independent medical practitioners. In Britain, students spend their sixth year in hospitals as pre-registration house officers (PRHOs), although this training is still the responsibility of university medical schools. In North America students complete four years of basic science and clinical training.

\section{CURRICULUM OVERLOAD}

The way in which traditional curricula are organised and taught as independent blocks of factual knowledge has contributed to curriculum overload. Much of the information is irrelevant to the rest of the medical course or to student's future careers. Lack of integration between the two-year pre-clinical basic science course and subsequent clinical learning is known, pejoratively, as the 'preclinical/clinical divide'. When clinical practice is eventually introduced, students are expected to make conceptual links between specialised scientific knowledge and its relationship with human disease processes in an unplanned and unstructured way. This has long been recognised as an ineffective way of learning that forces students to use 'surface' learning techniques that train the memory but not the mind. ${ }^{19}$ Knowledge gained in this way does not encourage critical thinking processes and is invariably forgotten. ${ }^{20}$ Students memorise facts and become passive learners to satisfy an intensive examination-driven system. The motivation, enthusiasm and curiosity that students bring with them as entrants to their courses are soon stifled under this sometimes intolerable burden. ${ }^{21}$

\section{MAINTAINING INTEREST AND ENTHUSIASM}

Enthusiasm and motivation can be maintained by encouraging students to explore aspects of medicine that interest them. Traditional curricula in most medical schools, both in Britain and abroad, provide limited opportunities for students to pursue their own interests, to develop areas of knowledge and skills that encourage motivation and independent learning, and to communicate well with patients and colleagues. The $1993 \mathrm{BBC}$ television programme, 'Doctors to $b e$ ', confirmed other research evidence that many junior doctors in Britain were dissatisfied with both their choice of career and the failure of their basic training to prepare them for real-life medicine. ${ }^{22-24}$ Undergraduate curricula must prepare students adequately for the future psychological and social demands of their profession.

widening educational settings in which education now has to take place

- national health priorities as the context for education

- active learning throughout life (with appropriate reforms in the examination system)

- professional competence as the purpose for all learning

- training of medical teachers as educators

- health promotion and prevention of illness

- integration of science and clinical practice

- selection of entrants, for non-cognitive as well as intellectual attributes

- co-ordination of education with health delivery services

- balanced production of the national need for doctors

- co-operation of the health professions (the issue of multi-professional training)

- $\mathrm{CME}$ as a main sphere of medical education

\section{Recommendations for change}

Medical education may be viewed as a learning continuum that only ceases at the end of doctors' professional lives. This idea retains a central position in recent recommendations for undergraduate and postgraduate training.

GENERAL MEDICAL COUNCIL RECOMMENDATIONS

Following an international conference in 1988, the World Federation for Medical Education (WFME) issued the Edinburgh Declaration of 12 principles for reforming medical education (box 1$).{ }^{7}$ Five years on, the recommendations of the World Summit on Medical Education were published under five major headings (box 2). ${ }^{25}$ The 12 principles have since influenced curriculum development throughout the world and are echoed in the recent recommendations of the General Medical Council (GMC) for the reform of undergraduate medical education in the UK. ${ }^{26}$ Like the WFME, and other bodies before it, the GMC expressed serious concern about the limited implementation of previous recommendations. ${ }^{27,28}$ The GMC believes that changing the style of undergraduate courses in line with their recommendations will 'bring about a reduction in the overload' that has been the focus of so much concern (box 3). The Calman Report on postgraduate training endorses the concept of a learning continuum and paves the way for substantial changes in the structure and content of postgraduate education and training. ${ }^{29-31}$ For example, universities must now ensure that each PRHO is allocated an educational supervisor from the 
Categories of recommendations of the World Summit on Medical Education ${ }^{25}$

- practice and policy

- the educational response

- the continuum of medical education

- partners in learning

- settings in learning

Box 2

Tomorrow's doctors: principle recommendations

- substantially reduce factual information

- promote learning through curiosity and exploration

- develop attitudes and attributes appropriate to professional responsibilities towards patients and colleagues

- develop clinical skills needed to enter the pre-registration year

- define a core curriculum of essential knowledge, skills and attitudes

- develop students' personal interests through in-depth special study modules

- introduce integrated and systems-based curricula to eliminate the pre-clinical/clinical divide

- emphasise communication skills throughout the course

- include public health medicine as a prominent part of the course

- provide opportunities for students to experience both community and primary health care as well as hospital-based services

- incorporate modern educational theory and technological resources into the learning system

- develop assessment methods appropriate to the new learning system that discourage the uncritical acquisition of facts

- establish representative and effective supervisory structures to design, implement and continue reviewing curricula

- ensure implementation of the recommendations: by the GMC making regular visits, obtaining progress reports and if necessary, by exercising statutory powers

Box 3 consultant body, who will control, supervise and monitor all aspects of their progress. In response to the Calman Report, the Association for the Study of Medical Education published proceedings of its April 1993 conference on the future of medical specialist training in the UK. ${ }^{32}$

\section{Content of medical education}

In its widest sense, the medical curriculum includes the aims of the course, what is learned (content), how the content is learned (learning strategies and methods), how students are assessed, and how all of these things are organised. One solution put forward by the GMC to 'enhance attitudes to learning', 'reduce overload', and for students to 'take greater responsibility for their own education', is to re-organise the curriculum using a 'core plus options' approach.

\section{A 'CORE' CURRICULUM}

The definition of a 'core' curriculum comprising basic knowledge, skills and attitudes needed by all doctors in the twenty-first century, whether they become generalists or specialists, is an onerous task. The approach recommended by the GMC in Britain is for medical schools to adopt a structured sequential framework in which a 'core' curriculum of identified knowledge, skills and attitudes is complemented by a system of 'special study modules', allowing students to pursue their personal interests. The core might be developed around a number of themes (eg, man and society, human disease, the public health), to encourage multi-disciplinary approaches to clinical problem-solving, develop critical thinking abilities, and promote attitudes conducive to continuing professional development. The integration of all disciplines throughout a course enables learning to focus, for example, on body-systems, patient management problems or particular clinical skills. Conceptual links can then be made between all aspects of learning and students acquire an understanding of their relevance to the whole course. Reaching such goals requires collaboration and co-operation between scientists and clinicians so that a balance between basic science and clinical learning at each level of the course can be achieved, thereby eliminating the pre-clinical/clinical divide.

Although the GMC has included a general set of learning objectives for 'Tomorrow's doctors' (box 4), ${ }^{26}$ there is a reluctance to define a 'national core' as this 'might promote undesirable rigidity and resistance to change'. Decisions about core content are left to individual schools in the hope that they will share experiences and ideas with each other and with professional bodies. ${ }^{33}$ It is hoped that a consensus opinion will eventually emerge. ${ }^{34}$

The GMC report strongly emphasises the inclusion of communication skills and the need for students to gain an understanding of computer technology as a learning tool. New curricula should also provide opportunities for students to learn in a variety of settings in the community, eg, clinics, general practices, health centres as well as hospitals, to gain an understanding of non-medical aspects of health-care and of the psychosocial aspects of medicine by incorporating the behavioural sciences throughout courses. There are also strong arguments for incorporating medical ethics into learning activities. ${ }^{35}$

Recent European recommendations for medical students to acquire proficiency in a second European language or to explore personal interests such as mathematics or music, can be developed through special study modules. ${ }^{15}$

\section{Learning strategies and methods}

The introduction of wholesale curriculum change into a medical school with a 'conventional' structure is possible, although difficult. ${ }^{36}$ Most institutions can demonstrate 'good' as well as 'not-so-good' practice and retaining parts of courses that function well and satisfy particular aims and objectives may be a preferred course of action, especially if they can be integrated successfully into a co-ordinated framework. ${ }^{37}$

\section{TRADITIONAL AND PROGRESSIVE STRATEGIES}

There are a number of learning strategies that schools can use in curriculum development, eg, teacher- or learner-centred, multi-disciplinary or subjectbased, system- or problem-based. The SPICES model describes curriculum change as a set of six issues. ${ }^{38}$ Each issue is represented as a continuum (box 5). The model places newer 'progressive' schools to the left of the continuum and the older 'traditional' schools to the right. It suggests that schools need not adopt a wholesale approach to curriculum change, but can decide where they stand on each continuum and where they would like to be in relation to the issues. There are, however, parts of curricula that are inextricably linked. Curriculum planners 


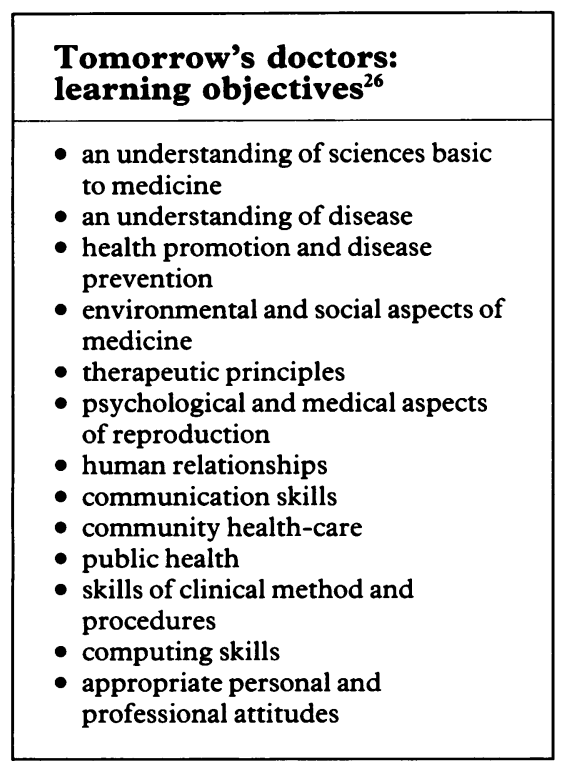

Box 4

\section{Educational strategies - the SPICES model ${ }^{38}$}

Student-centred........teacher-centred Problem-based.information-gathering Integrated.................. discipline-based Community-based........hospital-based Electives.............standard programme Systematic......... apprenticeship-based or opportunistic

Box 5

\begin{tabular}{|l|}
\hline Principles of adult learning \\
\hline Learners need to: \\
- build on previous learning \\
- identify their learning needs \\
- be involved in planning their \\
learning \\
- evaluate their learning
\end{tabular}

Box 6

\section{An example of a PBL case} used at the University of Liverpool

Maria is 50 years old. She has two daughters aged 18 and 23, is divorced and is looking after her 82-year-old mother. She was called for screening by the National Health Service Breast Screening Programme last week and was recalled to the assessment clinic. She has been told that she has a suspicious lesion in the left breast. need to be aware that changes made to one part of a learning system will invariably affect other parts. There may be unintended as well as intended consequences. ${ }^{39,40}$

\section{COMMUNITY- OR HOSPITAL-BASED}

More than half of all medical students in Britain become general practitioners. Traditional clinical teaching is centred in hospitals where only $5 \%$ of the population are treated. Trends towards increased use of the community for undergraduate teaching provide students with a broader view of health-care ${ }^{41,42}$ Community-based teaching (through departments of general practice or primary care) has largely taken the lead in the provision of student-centred and self-directed learning. ${ }^{43}$ Such teaching reflects progress in postgraduate vocational training for general practice, and offers not just a large pool of patients but also a cadre of experienced clinical teachers. ${ }^{44}$ Students can apply clinical and communication skills with a wide range of people, see for themselves, social, psychological, cultural and economic influences on health, and experience highly personalised teaching. This form of teaching is highly regarded by students. ${ }^{45}$

A few medical schools base their clinical courses in primary care (eg, University of New Mexico), others are developing such alternative pathways (eg, Harvard Medical School's proposed ambulatory medicine course), whilst many are gradually increasing the role of general practice attachments. The last 20 years have seen community teaching come of age. This is especially so in the UK where, starting from just one or two university departments, general practice teaching now occupies an important part in the experience of all British undergraduates. ${ }^{46}$ The University of Cambridge is experimenting with, and the University of Liverpool intend to introduce, up to $50 \%$ of clinical experience based in the community. ${ }^{47}$

\section{TEACHER- OR STUDENT-CENTRED}

Learning in most medical schools is still educationally 'conventional'. Courses are characterised by a teacher-centred approach, ie, by the teacher controlling the course content and method of presentation. Emphasis is on teaching rather than learning. In student-centred courses the learners are the key players and learning is based on principles of adult learning (box 6). They are encouraged to take greater responsibility for learning decisions and to question what and how they learn. ${ }^{48,49}$ Examples of other learner-centred methods include the use of learning contracts and mentors in postgraduate medical training. ${ }^{30}$ Task-based learning uses technical aspects of medicine to stimulate learning. ${ }^{50}$

PROBLEM-BASED LEARNING

The most widely adopted student-centred learning strategy in undergraduate medical education is problem-based learning (PBL). ${ }^{51,52}$ Its growth in medical schools can be traced to McMaster University Medical School (Hamilton, Ontario) in 1962 and to other schools since the early 1970s, eg, the University of Limburg Medical School (Maastricht, The Netherlands), the University of Newcastle (New South Wales, Australia), the 'New Pathway' at Harvard University and the New Mexico experiment. ${ }^{53-57}$

There are several definitions of PBL. ${ }^{58,59}$ When applied to medical education, patient problems are used to integrate basic sciences and clinical experiences (box 7). Through the analysis of problems students identify gaps in their knowledge, set learning objectives and, after self-study, apply newly gained information to problem-solving (box 8). To close the learning loop they evaluate the effectiveness of both the information collected and the way they managed the problem. In this way students use 'deep' approaches to learning as opposed to 'surface' approaches. Deep approaches increase understanding whereas surface approaches encourage rote learning and factual recall. ${ }^{60}$

PBL strategies require students to take primary responsibility for all aspects of the learning process. Small tutorial groups are combined with independent study as the main learning methods. ${ }^{61}$ Didactic methods of learning such as lectures are reduced and must be relevant. Problems used by students complement educational aims and objectives within each part of the course, often with a strong community orientation. Comparisons of traditional and innovative curricula identify that students learn differently, more satisfyingly, and without loss of biomedical competence in programmes using PBL. ${ }^{22,62}$

\section{THE TEACHER'S ROLE}

The introduction of PBL means that the traditional role of medical teachers must change in many ways. They have to adjust to a new set of institutional and educational values and adapt to new roles and relationships with their colleagues and students. Their autonomy as experts in a particular discipline is subsumed to 


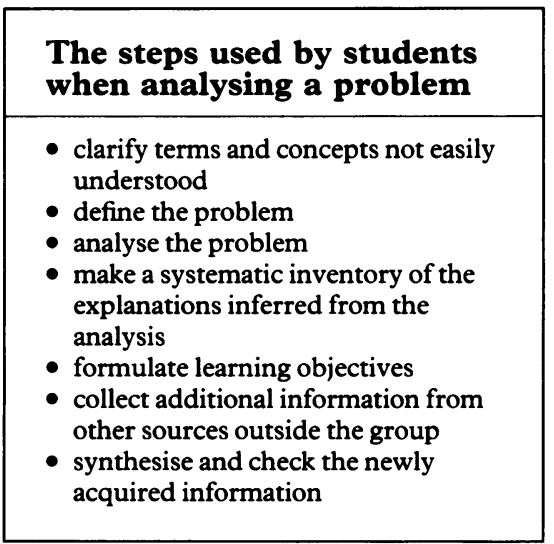

Box 8 working in interdisciplinary teams when designing and developing new learning and assessment materials. Tutors need to learn the dynamics of working as facilitators with small groups of students and learn to guide rather than control their learning. Loss of authority can be a threatening experience for some teachers and may result in a loss of confidence. It is essential that medical teachers are trained and socialised into their new roles. Extensive in-service training programmes must be part of the PBL strategy to enable tutors to continue to adapt and develop in a flexible way. ${ }^{63}$ Sir George Pickering's description of the role of the tutor in any branch of higher education, including medical education, is still relevant today:

'. . the aim should be to use the methods of education rather than instruction. Students
must be taught how to collect the facts, how to verify them, to assign a value to them, and
how to draw conclusions from them, and test the conclusions; in short, how to form a
judgment. The true aim of the teacher is to impart an appreciation of method rather than
a knowledge of the facts, for method is remembered when facts have been forgotten, and
method can be used when there are few facts. Students learn how to learn and can go on
acquiring knowledge for the rest of their lives.'
Pickering, $1958^{64}$

\section{PREPARING STUDENTS}

Students who are presented with PBL for the first time can also feel very unsure of themselves. As they become more familiar with the method the 'uncertainty combined with curiosity becomes the motivation to seek, to probe and to study'. ${ }^{65}$ There is, however, a need to structure students' understanding of PBL to facilitate the process rather than rely on them 'picking it up' in a random fashion.

\section{Assessment and evaluation strategies}

The introduction of innovative curricula means that different ways must be found to assess students and evaluate courses. Measuring the effectiveness of a course undergoing change is essential as a way of continuously improving teaching and learning.

\section{ASSESSMENT INFLUENCES LEARNING}

Assessment has a profound effect on the way students study. ${ }^{66,67}$ In an examination-driven system measuring factual knowledge, students adopt rote learning methods. In student-centred learning the learning process is more critical. Assessment methods are used to provide students with both formal and informal feedback on their progress. This is essential if they are to retain a central role in a continuous learning process. Such assessments are 'formative' and have a learning function. They are intended to help students to direct their efforts to those areas where progress is most needed. Assessment tools should be specific to the knowledge, skills and attitudes being assessed. They must also measure what they are intended to measure (ie, have reliability, validity and acceptability) and be consistent with the educational principles of the curriculum. ${ }^{68}$

\section{EVALUATION INFLUENCES TEACHING}

Like assessment, evaluation can be formative or summative. In the formative sense the function of curriculum evaluation is to provide information in a usable form to improve various aspects of a curriculum. This is a way of discovering any unintended effects that develop so that remedial action can be taken. Information derived from summative evaluation may be used to ensure that individuals and institutions are more accountable for their activities.

\section{Barriers to change}

Successful wholesale curriculum change in traditional schools include the Universities of Sherbrooke in Canada, Linköping in Sweden, and Harvard Medical School in the US. Others have been less successful. ${ }^{69}$ Innovations are difficult to implement in any organisation but medical schools, in particular, have characteristics that inhibit change. ${ }^{70,71}$

\section{POWER SYSTEMS}

Although they appear to be hierarchical with centralised power systems, medical schools are, in reality, structured and organised around individual disciplines. Remunerative structures often create conflicts of interest between individuals and departments so that research activities, clinical commitments and teaching obligations compete for time and status. Scant recognition for 'good' teaching has been the result. Existing values will need to be replaced by values which encourage and support interdisciplinary collaborative activities within medical 
schools and with other university departments, and which recognise and reward educational activities. Centralised systems are needed to plan and organise appropriate action and to implement and evaluate educational policies.

RESISTANCE TO CHANGE

Resistance will have to be overcome. There are always winners and losers during periods of change, and change in one part of a learning system will invariably affect other parts. Individuals may find it difficult to adopt a collaborative philosophy that dilutes their power and autonomy. Justified arguments will inevitably be put forward about time constraints, both to restructure curricula and to prepare new resource materials. Long-term benefits to students, staff and the medical school must be clear for ideas to become accepted. 'Ownership of change' by individuals is known to be a key factor of effective implementation. ${ }^{72}$

\section{PRACTICAL ASPECTS}

The third barrier to change lies in the practical aspects of introducing a student-centred learning system. Many variables can contribute to failure, eg, inappropriate management structures, inconsistent teaching quality through unfamiliarity, passive resistance to 'new' learning methods or inadequate learning resources. A staff development programme must be introduced and used before, during and after implementation, to identify and respond to such inconsistencies.

\section{MONITORING AND EVALUATION}

An effective and dynamic monitoring and evaluation system must be introduced as an integral part of medical schools' activities. Too often evaluation is relegated to a minor role and is ineffective and inadequate.$^{73}$ The introduction of innovative curricula will inevitably lead to the need for evaluation. If curricula are to be routinely reviewed and developed, evaluation must be accepted as a normal part of curricula activities.

\section{RESOURCES}

Finally, there is the question of funding. Whilst it may be possible to introduce some changes, undoubtedly, there is a need for extra resourcing or a diversion of existing funds. In Britain, the current use of SIFTR funds (Service Increment For Teaching and Research) and its Scottish and Irish equivalents by National Health Service Trusts, has been questioned. ${ }^{18,74}$ If community agencies other than hospitals are to be used as learning centres in new curricula, then a more sensitive distribution of these funds should be considered.

\section{The future}

'A core curriculum, designed to educate rather than to train, would be very different from that inflicted upon present-day undergraduates.' McCormick, $1992^{75}$

If, in identifying the core curriculum, medical schools succeed in reducing the content of undergraduate medical education, then earlier specialist training would be the result. Whilst in the UK special study modules broaden the learning experience, a four-year (and some would say even shorter) undergraduate education will prepare a competent young doctor capable of entering specialist training. Medical students wait a long time for clinical responsibility compared with their dental and nursing peers and shortening the preparatory period would be a welcome step. Against this, questions about student maturity, the pressure of early career choice and the ability of postgraduate training to deliver, are appropriate. Whatever the outcome, changes being introduced to curricula in the UK, Australia and North America promise to produce medical graduates with very different attitudes to those of today.

\section{Conclusions}

The need to redefine basic medical education has been fully recognised and accepted by medical schools around the world and educational principles on which curricula should be based have been put forward. Change is inevitable and schools now have to decide whether to opt for a wholesale change of curricula, change to selected parts of courses, or by the introduction of alternative tracks (eg, Harvard's New Pathway), as each approach brings with it a different set of implementation problems. Although there is ample empirical evidence to support student-centred learning methods, and some examples of wholesale successful implementation in traditional medical schools, there is still a need for caution and careful evaluation of new methods. Experiences of change need to be 
shared to inform understanding. If this is done, undergraduate medical education will make significant progress towards achieving its educational goals and providing communities with the doctors they need.

It is a pleasure to acknowledge the help of Professor Henry Walton in the preparation of this paper.

1 Medical Committee of Universities Funding Council. First report of the effects of NHS reform on medical and dental education and research. London: Universities Funding Council, 1991.

2 Medical Committee of Universities Funding Council. Second report of the effects of NHS reforms on medical and dental education and research. London: Universities Funding Council, 1991 .

3 Stocking B. Medical advances: the future shape of acute services. London: King's Fund, 1992.

4 Parry KM. Medical education worldwide. Med Educ 1985; 19: 487-02.

5 Walton HJ, Medical education worldwide: a global strategy for medical education: partners in reform. Ann Community-Oriented Educ 1993 6: $327-32$.

6 Marston RQ, Jones RM, eds. Medical education in transition. Commission on medical education. the sciences of medical practice. Princeton, New Jersey: The Robert Wood Johnson Foundation, 1992.

7 The Edinburgh declaration. Med Educ 1988; 22: 481.

8 Walton $\mathrm{HJ}$, ed. World summit on medical education: the changing medical profession Med Educ 1994; 28: suppl 1 .

9 United Nations Development Programme. Human Development Report. Oxford University Press, 1993.

10 Walton $\mathrm{HJ}$. The changing medical profession: implications for medical education. Med Educ 1993; 27: 1-2

11 Wyatt JC. Clinical data systems: components \& techniques. Lancet 1994; 344: 1609-14.

12 Stearns JA, Glasser $M$. How ambulatory care is different: a paradigm for teaching and practice. Med Educ 1993; 27: 35-40.

13 Lee PP. Models of excellence. Lancet 1994; 344: 1484-6.

14 Mant D. Prevention. Lancet 1994; 344: 1343-6.

15 Advisory Committee on Medical Training. Report and Recommendations on Undergraduate Medical Education. Brussels: Commission of the European Communities, 1993.

16 Walton HJ. Admissions procedures to medical Walton HJ. Admissions procedures

17 Powis DA. Selecting medical students. ASME Powis DA. Selecting medical students. ASME
medical education booklet no 26. Med Educ medical education

18 Lowry S. Medical education. London: BMJ Publishing 1994.

19 Walton HJ. The balance between education and training. Med Educ 1988; 22: 240-4.

20 Marton F, Saljö R. On qualitative differences in learning. 1 Outcome and process. $B r \mathcal{F} E d u c$ Psychol 1976; 467: 4-11.

21 Firth J. Levels and sources of stress in medical students. $B M \mathcal{F}$ 1986; 292: 1177-80.

22 Firth-Cozens J. Stress in medical undergraduates and junior house officers. $\mathrm{Br} \mathcal{f}$ Hosp Med 1989; 41: $161-4$.

23 Doctors to be. London: BBC Publishing Company, 1993.

24 Firth-Cozens J, Morrison LA. Sources of stress and ways of coping in junior house officers. 1989; 5: $121-6$.

25 Walton HJ, ed. WFME. Proceedings of the World Summit on Medical Education. Med Educ 1993; 28 (suppl 1) 140-9

26 General Medical Council (GMC) Education Committee. Tomorrow's doctors: recommendations on undergraduate medical education. London: GMC, 1993.

27 Association of American Medical and Dental Colleges. Physicians for the Twenty-First Century. Report of the project panel on the general professional education of the physician and college preparation for medicine. $\mathcal{F}$ Med Educ 1984; 59: Part 2.

28 Towle A. Critical thinking: the future of undergraduate medical education. London: The King's Fund, 1991.

29 Department of Health (DOH). Hospital doctors: training for the future. London: $\mathrm{DOH}, 1993$.
30 The Standing Committee on Postgraduate Medical and Dental Education (SCOPME) Teaching hospital doctors and dentists to teach. London: SCOPME, 1994.

31 Standing Committee on Postgraduate Medical and Dental Education (SCOPME). Making the most of formal opportunities for doctors and dentists in training. London: SCOPME, 1994.

32 Buckley EG, Walton $\mathrm{HJ}$, eds. Implementing Calman: the future of medical specialist training in the United Kingdom. Proceedings of the in the United Kingdom. Proceedings of the ASMDE conference held in London
1994. Med Educ 1994; 28 (suppl 2).

33 Bligh JG. Identifying the core curriculum: the Liverpool approach. Med Teacher 1995; (in press)

34 Lavelle S. Identifying the core curriculum: is there a scientific approach? Paper presented at the ASME meeting, December 1994, London.

35 Bryant JH. The moral ethos of medical education. Proceedings of the World Summit on Medical Education. Med Educ 1994; 28 (suppl 1): 38-42.

36 Des Marchais JE, Bureau MA, Dumais B, Pigeon G. From traditional problem-based learning: a case report of a complete curriculum reform. Med Educ 1992; 26: 190-9.

37 Harden RM. Ten questions to ask when planning a course or curriculum. Med Educ 1986; 20: ning a cour.

38 Harden RM, Sowden S, Dunn WR. Some educational strategies in curriculum development: the SPICES model. ASME Medical Education booklet no 18. Med Educ 1984; 18: 284-97.

39 Gale R, Grant J. Managing change in a medical context: some guidelines for action. London: The Joint Centre for Research and Development in Medicine, British Postgraduate Medical Federation, 1990.

40 Lindquist J. Strategies for change. Berkeley California: Pacific Sounding Press, 1978.

41 Oswald $\mathrm{N}$. Why not base medical education in general practice? Lancet 1989; 2: 148-9.

42 Glick SM. Problem-based learning and community-oriented medical education. Med Educ 1991; 25: 542-5.

43 Stanley IM, Al-Shehri A. What do medical students seek to learn from general practice? A study of personal learning objectives. $\mathrm{Br} \mathfrak{F} \mathrm{Gen}$ Pract 1992; 42: 512-6.

44 Lefford F, McCrorie P, Perrin F. A survey of medical undergraduate community-based teaching: taking undergraduate teaching into the community. Med Educ 1994; 28: 312-5.

45 Cooper CW. Medical students' perceptions of an undergraduate general practice preceptorship. Fam Pract 1992; 9: 323-9.

46 Howie J, Hannay D, Stevenson J. General practice in the medical schools of the United Kingdom: the Mackenzie report. Edinburgh: Department of General Practice, 1986.

47 Saunders S. Curriculum change, a student's perspective. Student BMF 1994; 2: 256-7.

48 Kerspective. Student BMf 1994; 2: 256-7. from pedagogy to androgogy. Cambridge, USA: Cambridge Book Company, 1970.

$49 \mathrm{Kolb}$ DA. Experiential learning. Englewood Cliffs, New Jersey: Prentice-Hall, 1984

50 Bligh JG, Harden RM. Bridging the gap between hospital experience and general prac-
tice vocational training. Med Teach 1990; 12: 169-73.

51 Norman GR, Schmidt $H$. The psychological basis of problem-based learning: a review of the evidence. Acad Med 1992; 67: 557-65.

52 Albanese MA, Mitchell S. Problem-based learning: a review of the literature on its outcomes and implementation issues. Acad Med 1993; 68: 52-81.

53 Neufeld VR, Barrows HS. The McMaster philosophy: an approach to medical education. $\mathcal{f}$ Med Educ 1974; 49: 1040-50. 4 Tosteson DC. New pathways in general medical
education. $N$ Engl $\mathcal{F}$ Med 1990; 322: 234-8.
55 Clarke RM. Curricular innovation at a new medical school at Newcastle, Australia. Proceedings of the 1977 Conference of the Association of Medical Education in Europe. Med Educ 1978 ; i: $1262-5$

56 Wetzel MS. Problem-based learning: an update on problem-based learning at Harvard Medical School. Ann Community-Oriented Educ 1994; 7: 237-47.

57 Kaufman A. The New Mexico experiment: educational innovation and institutional change. educational innovation and in
Acad Med 1989; 64: 285-94.

58 Walton HJ, Matthews MB. Essentials of problem-based learning. Med Educ 1989; 23: 542-58.

59 Barrows HS, Tamblyn RN. Problem-based learning. New York: Springer Publishing Company, 1980.

60 Newble D, Clarke R. The approaches to learning of students in a traditional and an innovative problem-based medical school. Med Educ 1986; 20: 267-73.

61 Schmidt H. Foundations of problem-based learning: some explanatory notes. Med Educ 1993; 27: 422-32.

62 Moore GT, Block SD, Style CB, Mitchell R. The influence of the new pathway curriculum on Harvard medical students. Acad Med 1994; 69: 983-9.

63 Moust JHC, de Grave WS, Gijselaers WH. The tutor role: a neglected variable in the implementation of problem-based learning. In: Nooman ZM, Schmidt H, Ezzat ES, eds. Innovation in medical education: an evaluation of its present status. New York: Springer Publishing Company, 1990; pp.135-51.

64 Pickering G. Medicine's challenge to the educator. $B M Y$ 1958; 2: 117 .

65 Van Aalst E, Chatrou E, Noten A, Thoonen B. Problem-based learning from the student perspective. In: van der Vleuten $C$, Wijnen W, eds. Problem-based learning: perspectives from the Maastricht experience. Amsterdam: Thesis, 1990; pp.77-81.

66 Newble DI, Jaeger K. The effect of assessments and examinations on the learning of medical students. Med Educ 1993; 17: 165-71.

67 Coles CR. Differences between conventional and problem-based curricula on their student's approaches to learning. Med Educ 1985; 19; 308-9.

68 Van de Vleuten C, Verwijnen M. A system for student assessment. In: van der Vleuten C, Wijnen W, eds. Problem-based learning: perspectives from the Maastricht experience. Amsterdam: Thesis, 1990; pp. 27-49.

69 Schwartz PL, Heath CJ, Egan AG. The art of the possible. Dunedin: University of Otago Press, 1994.

70 Coles CR, Grant J. Curriculum evaluation in medical and health-care education. ASME medical education research booklet no 1 . Medical education. London: The Joint Centre for Research and Development in Medicine,

71 Bloom SW. The medical school as a socia organization: the sources of resistance to change. Med Educ 1989; 23: 228-41.

72 Gale R, Grant J. Guidelines for change in postgraduate and continuing medical education. Development in Medicine, 1990.

73 Brookfield S. Understanding and facilitating student learning. Milton Keynes: Open University Press, 1986.

74 Research and Development Task Force. Supporting research and development in the NHS porting research and development in the

$75 \mathrm{McCormick}$ J. The contribution of general practice. In: Downie RS, Charlton B. The making of a doctor. Oxford University Press, 1992. 